\title{
Smart Sewers 1: Sewer Configuration at Rural Houses
}

\section{Rodney McDermott ${ }^{*}$, W. Alan Strong1, Philip Griffiths ${ }^{1}$, Kim Littlewood², Michael G. Doherty ${ }^{3}$}

${ }^{1}$ Belfast School of Architecture and the Built Environment, Ulster University, Belfast, Northern Ireland ${ }^{2}$ Open University, Milton Keynes, UK

${ }^{3}$ MAST Construction Limited, Buncrana, Co. Donegal, Ireland

Email: ${ }^{\star}$ r.mcdermott@ulster.ac.uk

How to cite this paper: McDermott, R., Strong, W.A., Griffiths, P., Littlewood, K. and Doherty, M.G. (2020) Smart Sewers 1: Sewer Configuration at Rural Houses. Journal of Water Resource and Protection, 12, 825-834. https://doi.org/10.4236/jwarp.2020.129048

\section{Received: July 12, 2020}

Accepted: September 27, 2020

Published: September 30, 2020

Copyright (c) 2020 by author(s) and Scientific Research Publishing Inc. This work is licensed under the Creative Commons Attribution International License (CC BY 4.0).

http://creativecommons.org/licenses/by/4.0/

\begin{abstract}
The layout of houses and other buildings impacts the way in which foul sewer pipework is positioned internally and externally. Less water to waste through conservation measures reduces the distance that gross solids transfer in sewers and increases the number of sewer blockages. Dwelling houses are often laid out where the solids from faecal flushes are at the head of the sewer line with other flows entering downstream. Discharges from appliances such as washing machines, dishwashers, baths, showers and kitchen/utility sinks are often not utilised in the transfer of the gross solids when they enter downstream of the faecal flushes. At present, no recommendations or specific design guidance exist regarding the design of internal building layouts relating to sewer configuration requirements. Furthermore, to date, no specific research exists which examines pipeline configuration scenarios outside buildings in terms of the link between multiple grey water discharge points and solid transfer in a sewer system. The aim of this study was to investigate sewer layout at houses in terms of maximising greywater flow in relation to solid transfer. This study showed that smart sewers are needed which utilise all the foul water leaving a building as it was found that up to $100 \%$ of greywater in some instances is completely missed out in terms of solid transfer. Consequently, optimal sewer design is far from being realised and internal building layouts should be designed with consideration of the faecal flushes and greywater flows.
\end{abstract}

\section{Keywords}

Sewer Blockages, Design, Configuration, Water Conservation, Greywater, Energy and Solid Transfer 


\section{Introduction}

This is novel and original research because this type of in-situ investigative survey at existing properties to distinguish between greywater and faecal flush flow directions has not been reported on before. The concept of water mobility and its public health benefits has existed even before the early and distinctive work of Joseph Bazalgette [1]. Furthermore, water conservation has been cited in several government strategies and articulated by the Environment Agency 2008 [2]. Water conservation through reduced Water Closet (WC) flush volumes reduces the distances that solids travel and can increase sewer blockages [3].

This paper adds knowledge and understanding to maximise the use of water, reduce sewer blockages and, thereby, enhance the environment which is a critical element of the sustainability aspirations as explained in the UN Sustainable Development Goals (SDG) (Strong \& Hemphill) [4]. This study is set in the context of these global and local goals and specifically with reference to SDG Goal 6 which sets out to "Ensure availability and sustainable management of water and sanitation for alp". The paper delivers the results from this pipeline configuration investigation and reports on the foul pipework configuration from 112 rural dwelling houses. The in-situ surveys found that the location and amount of foul sewer outlets from the houses varied significantly. Greywater recycling for other uses should not be impeded; however, more research is required on the optimum layout of foul pipes at houses including greywater recycling/diversion options. The results in this study show that foul pipeline configuration is a key component in water usage to aid solid transfer in sewers. Reference to pipelines, sewers or sewer lines herein is taken to mean foul pipelines outside buildings.

\section{Literature Review}

In the Republic of Ireland (ROI), Part $\mathrm{H}$ of the Building Regulations (Heritage and Local Government, 2010) provides information on the minimum gradients of pipelines and asks designers to consider increased risk of sewer blockages where flush volumes of less than 5 litres are used [5]. In England, Part $\mathrm{H}$ of the UK Building Regulations (The Department for Communities and Local Government, 2015) covers drainage and waste disposal and supersedes Part $\mathrm{H}$ of the UK Building Regulations (Office of the Deputy Prime Minister, 2002). The 2002 regulations highlighted that one of the changes from the 1992 version relating to wastewater was guidance on design of sanitary pipework to serve low flush WCs. In the 1992 version, one of the basic performance requirements was that the pipework operated without blocking. The 2015 version of the regulations states that the layout of the drainage should be kept simple [6]. Whilst both the England and ROI regulations refer to low flush WCs and consideration of the same in design, these regulations do not specifically advise designers on the configuration of sewers to make use of avail- 
able water to increase solid transfer distances. The British Standards Institution (BSI) (2017) BS EN 752: 2008 provides detailed guidance on "Drain and sewer systems outside buildings"; Annex D provides information on the "physical layout of the system" but does not make reference or allude to sewer layout and the making use of the water discharges [7].

Water conservation interventions are increasing; however, sewer blockages are also increasing. McDermott et al. (2019) presented a literature review on solid transfer research on low flow sewers from the mid-20 ${ }^{\text {th }}$ Century to 2019 [8]. One of the recommendations for further research was that building regulations need to revise foul pipework configuration. This paper is the output from this clearly defined research gap.

\section{Method}

Ethical approval for this study was granted by Ulster University due to the procedure involving contact with house occupiers. Detailed risk assessments were completed relating to the surveying of sewers at houses and covered hazards which included wastewater; vermin; sharp objects; buried structures; electricity; guard dogs; manual handling; and overgrowth/brambles.

A total of 187 house occupiers were contacted of which 112 were reported on. This involved detached and semi-detached houses in rural locations on the Inishowen Peninsula, County Donegal, Republic of Ireland. Permission was asked from the occupier/owners to carry out a survey. Where possible, the survey involved opening access junctions (AJs)/chambers to determine the flow regime. Where the flow regime could not be readily established, dye (Wardsflex) was used. Dye testing was used on $29.47 \%$ of the properties surveyed and proved useful in determining flow direction. The water volumes used in the calculation procedure for greywater were adapted from McDermott [9] based on discharge volumes from each flow source.

The planning portal of the local authority (Donegal County Council) was also used as a proxy method to assess pipeline configuration using proposed house plans. All planning applications over a 5-year period can be viewed online. It was envisaged that this method would eliminate time-consuming field/in-situ surveys. Whilst not part of the overall aim, the survey also noted the condition of the AJs. If any three of the following deviations existed, the AJ was determined as being in poor condition:

1) Cover damaged

2) Cover not fitting

3) Structure damaged

4) Benching damaged or non-existent

5) Inlets damaged

6) Pipe/channel damaged

Standing water or a blockage was not involved in the condition assessment as blockages can be formed by flushing inappropriate or unsuitable items [9]. 


\section{Results}

House occupiers for 31 homes out of the 187 contacted did not consent; therefore, 156 houses were visited. Of these, 44 could not be reported on due to the limitations provided in Section 5.4.2. It should be noted that out of the 112 houses reported on, 29 houses were in a housing development. It was established that the pipeline configuration was the same at all except one of the properties. This appeared to have been due to alterations made to the property because of a building extension.

\section{Existing Foul Pipeline Configurations}

Table 1 shows the results from the field surveys. The percentage of greywater is an approximation based on the discharge volumes. The results from the field tests with a "foul outlet" taken as single pipe from the house to the lateral/collection pipe. It should be noted that one single foul outlet can be used to convey multiple discharges. These multiple discharges examples included: 1) 2 WCs (first floor and ground floor) combined in one outlet pipe, and 2) utility room sink, dishwasher and washing machine going into a gully/one outlet pipe. Where there was a WC, there were normally two separate outlets: one for the WC and one for the wash hand basin and shower (if any).

\section{Discussion of Results}

\subsection{Pipeline Configuration at Existing Houses}

Table 1 reports an average of circa 30\% of the greywater leaving the 112 houses discharging upstream of the first WC discharge. This figure dropped to circa $12 \%$ for the group of 43 houses that had six foul outlets. Over $20 \%$ of the greywater discharges occurred downstream of all WC discharges; therefore, the solid transfer of faecal or sanitary flushes was not aided. One of the houses in the two

Table 1. Results summary from field surveys.

\begin{tabular}{cccc}
\hline $\begin{array}{c}\text { Foul Outlets (Nr) } \\
\text { (From Field Visits) }\end{array}$ & $\begin{array}{c}\text { Nr of } \\
\text { Houses }\end{array}$ & $\begin{array}{c}\text { Greywater entering upstream of } \\
\text { the first upstream solid/WC } \\
\text { discharge }\end{array}$ & $\begin{array}{c}\text { Greywater entering downstream } \\
\text { of the last downstream solid/WC } \\
\text { discharge }\end{array}$ \\
\hline 8 & 4 & 7.016 & 12.608 \\
7 & 19 & 18.065 & 6.344 \\
6 & 43 & 12.254 & 8.210 \\
5 & 28 & 27.650 & 15.569 \\
4 & 15 & 30.542 & 24.035 \\
3 & 1 & 65.215 & 34.785 \\
2 & 2 & 50.000 & 50.000 \\
1 & 0 & NA & NA \\
Average= & & $30.106 \%$ & $21.650 \%$ \\
Standard Deviation & & 20.942 & 15.893 \\
\hline
\end{tabular}


foul outlets category had $100 \%$ of the greywater downstream of the WC outlet. Whilst not included in the aim of the survey, circa $21 \%$ of the AJs/chambers were in poor condition and $8.3 \%$ of the sewers were partially blocked to the extent that a survey could not be completed.

The planning portal from Donegal Co Council provided a considerable finding in terms of what was planned for sewer layouts and the "as built". The limitation to taking information from the house plans is that the pipeline configuration as built may not necessarily match the plans submitted for planning permission. The actual sewer layout plan for the housing development (29 houses) did not match the as built layouts that were surveyed with considerable variability. When other once-off house plans were looked at on the planning portal, the sewer configuration was indicative or not shown at all. These are important findings as it shows that there are instances where the foul sewer layout is being left to the house builders and demonstrates that plans and as built do not always match.

\subsection{Designers' Role}

Designers should plan houses and other buildings to facilitate useful water from fixtures other than WCs to enter the discharges upstream of the solids entrance to the foul pipelines. The following points should be noted:

1) The direction of flow depends on several variables including topography and the location of the existing sewer network. These are important whilst there are considerable possible alternative physical layouts for sewers outside buildings.

2) Figure 1 shows the flow direction in external foul pipework that typically was found during the surveys, where the gravitational kinetic energy from the

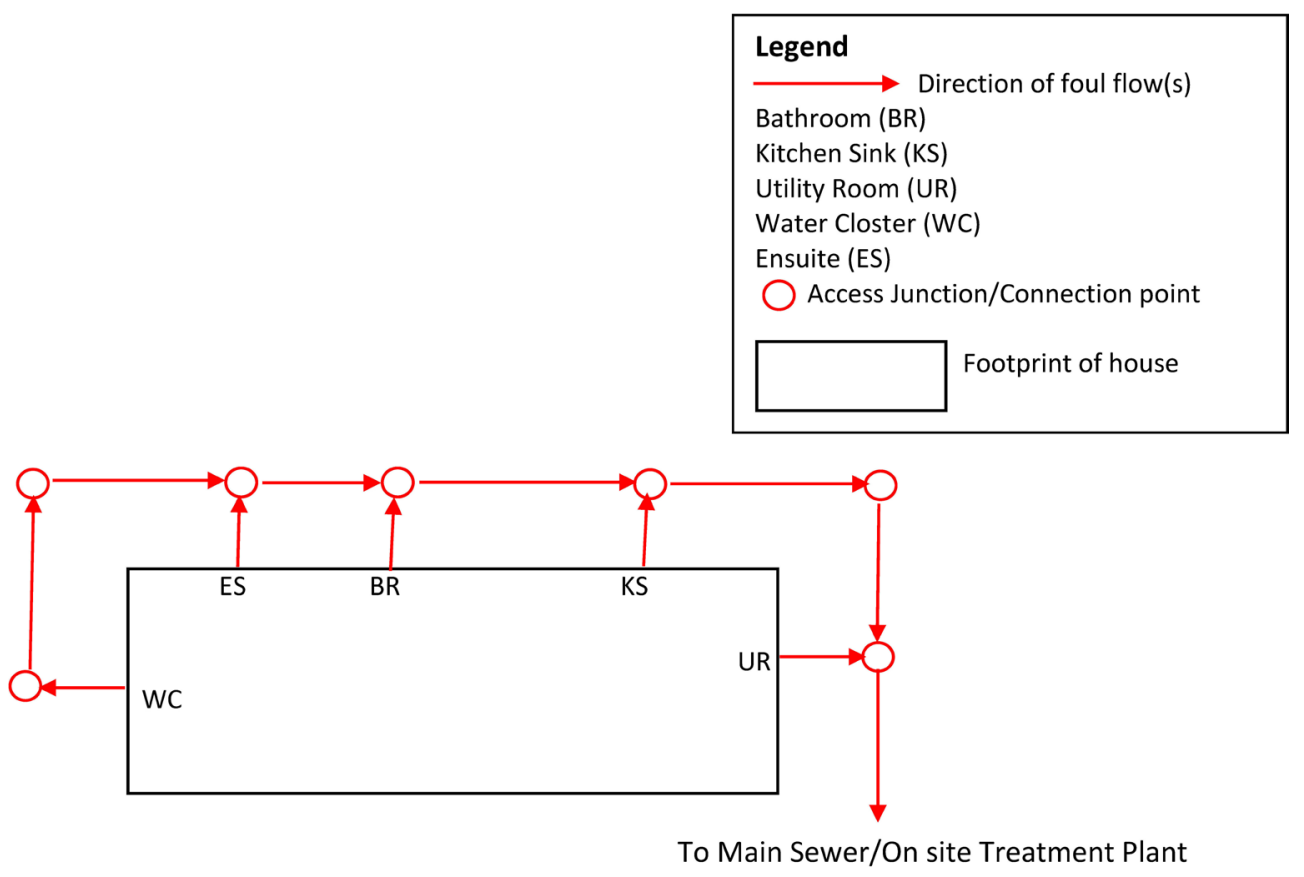

Figure 1. House plan schematic showing flow direction of external foul pipework. 


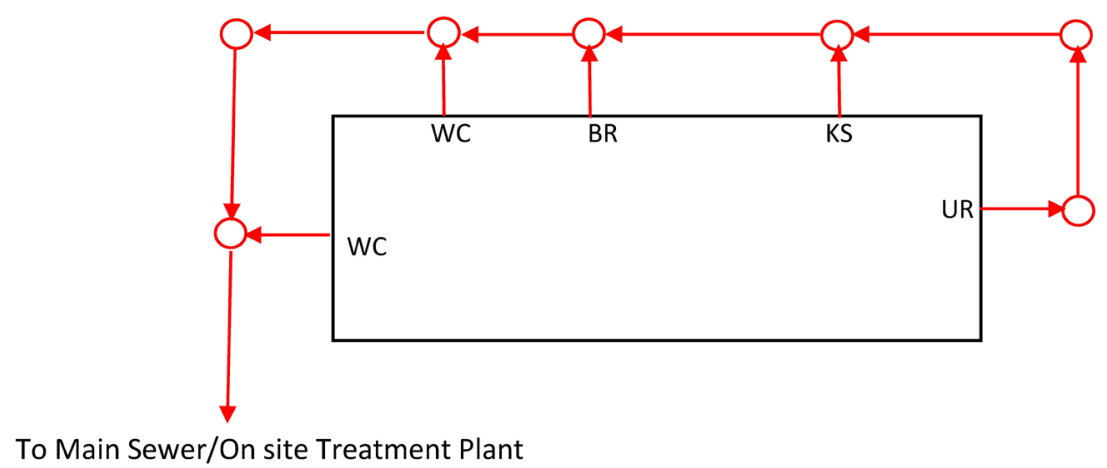

Figure 2. House plan schematic showing revised flow direction of external foul pipework.

useful water from the bathroom, kitchen sink and utility room were lost. Figure 2 shows how a simple change in direction of the foul pipework made use of these outlets in terms of solid transfer from WCs. This option shown in Figure 2 also assists with the option of greywater recycling, if feasible. The layout of locations that have WC such as bathrooms and ensuites within themselves is an important consideration to ensure that the greywater discharge is upstream of the WC discharge.

Marlow et al. (2011) reported that sewer diameter is one of the most significant factors in relation to sewer blockages [10]. This claim is based on analysis from two water companies in Australia. The analysis included approximately $13,000 \mathrm{~km}$ of sewer network with pipework of $300 \mathrm{~mm}$ diameter and under and concluded that $100 \mathrm{~mm}$ diameter pipes were the cause of most blockages. Furthermore, the report highlighted that increased diameter pipes reduced the probability of blockages. Typically, the foul pipework diameter around houses is $\leq 150 \mathrm{~mm}$. Arthur et al. (2008) report that sewer blockages occurred in pipes of less than $225 \mathrm{~mm}$ diameter. This information was based on data relating to a catchment in southern England of $30.8 \mathrm{~km}$ of pipeline, serving a town with a population of approximately 10,000 people, approximately $86 \%$ of the pipes were $150 \mathrm{~mm}$ to $300 \mathrm{~mm}$ diameter [11]. The method to address domestic sewer design is to consider pipeline configuration by reference to exemplar diagrams (Figure 1 and Figure 2) to highlight options and a checklist as part of building regulations. The Environment Agency's (2008) Less Water to Waste report called for more informed guidance to ensure that "water efficiency" is analysed whilst also looking at the "bigger picture" in terms of considering sewer design [9]. Water conservation is now becoming critical in parts of the UK and Ireland. A cross-party report in 2018 urged the UK government to champion water efficiency in the built environment and specified a 100-litre water usage per person per day to make green infrastructure "the norm" [12]. There is a risk that some parts of England could run out of water within 20 years [13] and because water conservation impacts solid transfer, sewer design needs be updated as a matter of urgency.

\subsection{Designers' Smart Sewers Checklist}

The authors believe that the following simple 6-item checklist should be incorporated into Irish and UK building regulations: 
1) Does the internal pipework layout of the building allow for maximum use of the greywater to assist solid transfer?

2) Does the external pipeline configuration make maximum use of the hydraulic movement of greywater?

3) Are there other options available in terms of flow direction that may maximise the available gravitational kinetic energy from water to assist in clearing solids and reduce potential pollution whilst conserving water?

4) Does the greywater from the ensuite discharge upstream of the ensuite WC outlet?

5) Does the greywater from the bathroom discharge upstream of the bathroom WC outlet?

6) Is the utility room pipework located to make maximum use of surfactant dosed water?

\subsection{Limitations and Other Considerations Relating to the Study}

\subsubsection{Limitations in Consent to Access to Survey Houses}

Of the 187 property owners contacted, 31 (16.6\%) did not consent to a survey. There were varying reasons for consent not being forthcoming despite a detailed explanation of the survey and what it entailed. Anecdotally, these possibly included human nature, anonymity and fear of the unknown. Despite clear explanation, it became evident in discussion that there are social issues related to water charging that may impact people's thought process [14]. These include house occupiers questioning if the survey was trying to establish the volume of water they were using. Hence, the ethical approval process is important in screening potential issues and the option for decision-making of not to proceed.

\subsubsection{Limitations in Establishing the Flow Regime}

There were issues in establishing the flow regime. The results from 44 (28.2\%) houses out of 156 could not be reported due to the following reasons:

1) The flow regime could not be established as there were no AJ covers on some of the connection points where branch connections were carried out by using bends.

2) There was a health and safety issue associated with the survey where adequate control measures could not be implemented and an unacceptable risk still existed. This included, for example, a guard dog that could not be removed from the property or securely isolated temporarily at the property.

3) AJ covers could not be found/opened.

4) The flow regime could not be accurately established after opening the AJ cover(s) and using dye testing.

5) The sewer was blocked and the flow pattern could not be established in 13 properties (8.3\%) out of the 156 .

\subsubsection{Other Considerations}

1) Conventional chamber lifters could not be utilised to lift certain covers where the lifting eyes were damaged; therefore, other equipment for levering had 
to be used. Circa $21 \%$ of the AJs/chambers and their covers were in poor condition. For example, Figures 3-5 are from the first chamber at the first house surveyed. Figure 3 shows the chamber with the cover removed. This chamber had standing water with the next downstream chamber having no standing water. A check on the invert levels showed a back fall of $0.026 \mathrm{~m}$ between the invert level of both chambers. The cover frame is out of alignment as is the cover which can be seen in Figure 4 and Figure 5. It should be noted that there were chambers in considerably poorer condition. This led to actions that had to be taken including replacing nine covers where the existing covers could not be seated back into the

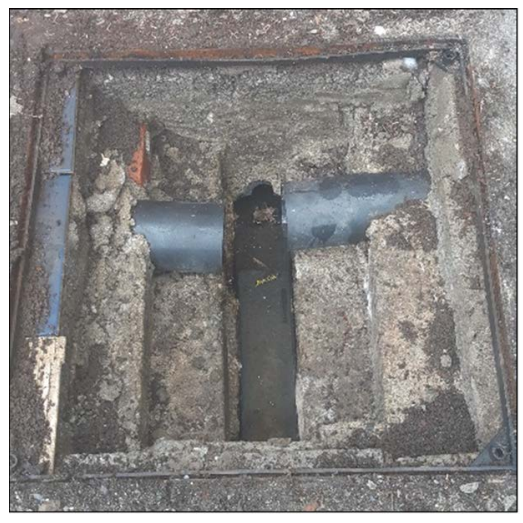

Figure 3. First chamber at the first house surveyed (H1 F1).

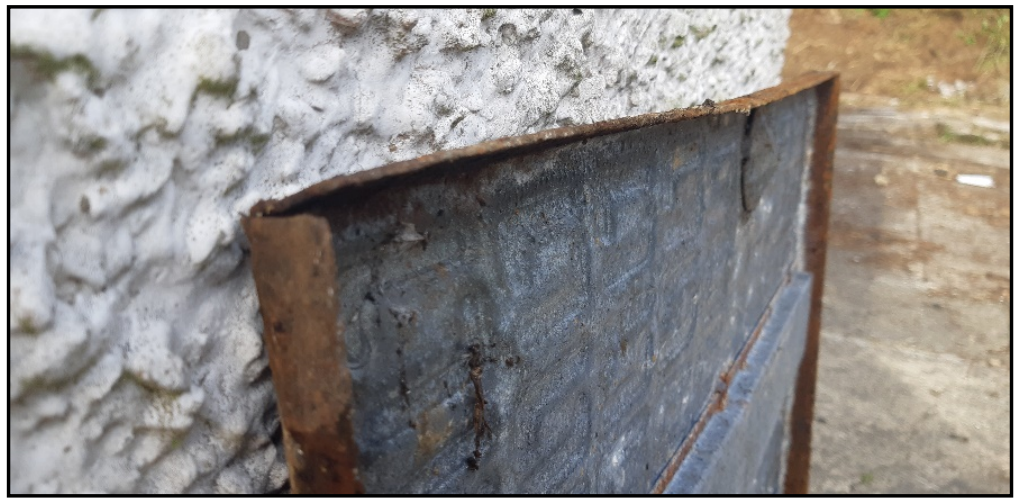

Figure 4. H1 F1 galvanised steel cover with damaged flange.

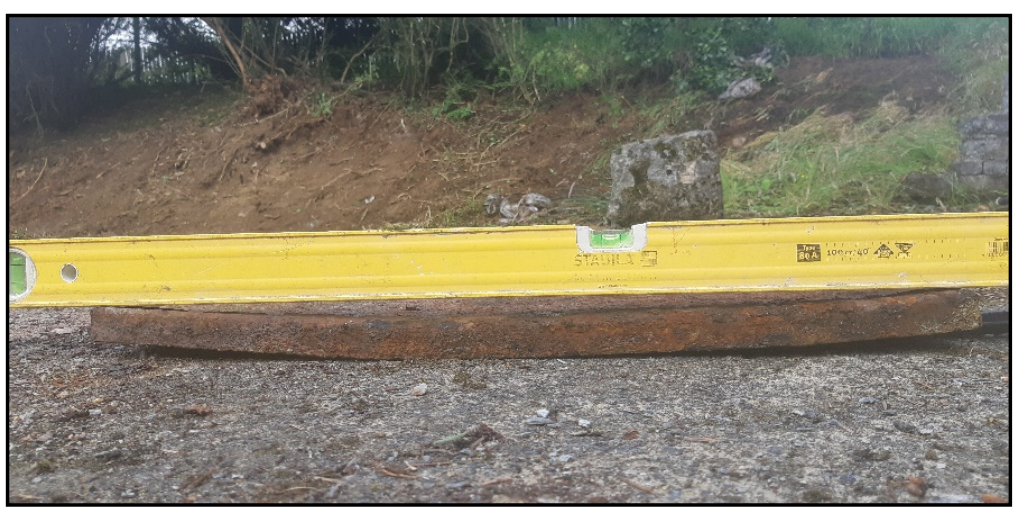

Figure 5. H1 F1 galvanised steel cover rusted and deflected. 
frame properly or where covers cracked upon removal. Replacing covers, particularly where a replica replacement cover is not available, can have considerable costs. This also applies when the cover is located under an asphalt or concrete surface. These issues influenced the speed of the survey work but did not challenge the integrity of the hydraulic findings.

2) The surveying of 112 houses was resource intensive in terms of the time required. There were surveys at individual houses that took more than two days each to successfully complete.

3) Several storm flows were connected into the foul lines creating combined sewers. These flows were not considered in the calculations.

\section{Conclusions}

As water conservation is on the increase, domestic sewer blockages are also increasing. Increased sewer blockages are not sustainable and can impact negatively on the environment, public health and the economy. Sewer blockages existed in $8.3 \%$ of the properties surveyed and circa $21 \%$ of the AJs/chambers surveyed were in poor condition. There are external sewer pipeline configurations around houses that are less than $10 \%$ efficient in terms of making discharge water from houses work to assist in moving solids. With up to $100 \%$ of greywater in some instances being missed out or non-functioning in solid transfer; therefore, prompt action must be taken. This water efficiency issue must be addressed and, where possible, greywater must not be allowed to bypass or enter downstream of the solid. Civil and building services engineers and planners must work together to create smart layouts for smart sewers. Significant issues related to the quality of the chambers and pipework were widespread with foul sewer layouts being left to the house builders as clear evidence was found that house plans and as built can have considerable configuration differences.

With claims being made that parts of England could run out of water within 20 years, less water to waste should be factored into sewer design. Water discharges from sources other than the WC are a vital source of gravitational kinetic energy to assist in transferring faecal solids along the foul pipelines. Sewer layouts can be both simple and effective by aiming to make maximum use of the greywater to aid solid transfer in sewers; therefore, smart designs are needed urgently to deal with impacts of water conservation on sewer performance.

In the UK and Ireland, future building regulations should include specific reference to pipeline configuration at houses and other buildings. Sewer design should be revised to allow useful water from sources such as dishwashers, washing machine, baths and showers to enter (where possible) upstream of the solids' entry point. The sewers that are designed must be smarter in terms of making use of the maximum volume of flow leaving the properties to reduce the negative impact of sewer blockages. This can be achieved by a mandatory designers' smart sewers checklist (Section 5.3) as part of the building regulations. 


\section{Recommendations for Other Work}

1) A range of internal layouts of houses should be investigated to assess the maximum gravitational kinetic energy from greywater in terms of solid transfer in sewers.

2) A similar survey reporting on foul layouts at urban houses.

3) Rig-based testing to establish optimum sewer layouts at houses.

\section{Conflicts of Interest}

The authors declare no conflicts of interest regarding the publication of this paper.

\section{References}

[1] Halliday, S. (2001) The Great Stink of London. Sutton Publishing, Gloucestershire.

[2] Environment Agency (2008) Less Water to Waste. Environment Agency, Bristol.

[3] Littlewood (2000) Movement of Gross Solids in Small Diameter Sewers. Unpublished PhD Thesis. Imperial College, University of London, London.

[4] Strong, W.A. and Hemphill, L. (2006) Sustainable Development Policy Directory. Blackwell, Oxford. https://doi.org/10.1002/9780470759479

[5] Department of Environment, Heritage and Local Government (2010) Building Regulations 1997 to 2010. The Stationery Office, Dublin.

[6] The Department for Communities and Local Government (2015) The Building Regulations 2010. Drainage and Waste Disposal. RIBA, Newcastle upon Tyne.

[7] British Standards Institution (BSI) (2017) BS EN 752: 2017. Drain and Sewer Systems Outside Buildings. BSI, London.

[8] McDermott, R., Strong, A. and Griffiths, P. (2019) Solid Transfer in Low Flow Sewers, the Distance Travelled So Far Is Not Enough. Journal of Environmental Protection, 10, 164-207. https://doi.org/10.4236/jep.2019.102011

[9] McDermott (2014) Water Conservation Impact on Solid Transfer in Sewers. Published PhD Thesis. Ulster University, Northern Ireland.

[10] Marlow, D.R., Boulaire, F., Beale, D.J., Grundy, C. and Moglia, M. (2011) Sewer Performance Reporting: Factors That Influence Blockages. Journal of Infrastructure Systems, 17, 42-51. https://doi.org/10.1061/(ASCE)IS.1943-555X.0000041

[11] Arthur, S., Crow, H. and Pedezert, L. (2008) Understanding Blockage Formation in Combined Sewer Networks. Proceedings of the Institution of Civil Engineers-Water Management, 161, 215-221. https://doi.org/10.1680/wama.2008.161.4.215

[12] George, S. (2018) Cross-Party Report Urges Government to Champion Water Efficiency in Built Environment.

https://www.edie.net/news/4/Cross-party-report-calls-for-Government-to-embed-w ater-efficiency-in-planning-policyl

[13] Lavelle, S. (2020) Parts of England Could Run out of Water within 20 Years, Warn MPs. The Guardian. 10 July.

https://www.theguardian.com/environment/2020/jul/10/parts-of-england-could-ru n-out-of-water-within-20-years-warn-mps

[14] McDermott, R., Solan, B., McCord, S. and Littlewood, K. (2019) Irish Water and Scottish Water: A Comparison. Journal of Water Resource and Protection, 11, 1064-1089. https://doi.org/10.4236/jwarp.2019.118063 